\title{
BULLYING, CAUSES AND WAYS TO CONFRONT IT
}

\author{
Asst. lecturer AFRAH TUAMA RADHI \\ Presidency of Al-Mustansiriya University \\ Department of control and internal audit
}

DOI: $10.37648 /$ ijrssh.v10i01.033

Received:26 ${ }^{\text {th }}$ October 2019; Accepted:01 ${ }^{\text {st }}$ December, 2019; Published: $17^{\text {th }}$ December, 2019

There has been a lot of talk recently about the phenomenon of bullying, bullying, or Thugs in different age groups, especially in some schools where some students are being bullied by colleagues out of fear, bullying, or imposing hegemony in order to show heroism to colleagues in order to control and consolidate the bullying phenomenon.

Bullying is defined as a form of violence, abuse, and victimization that is directed from one person or group of people to another person or group of people where the attacking person is stronger than the other person who may be through physical assault, actual harassment, and other violent methods, and it follows people The bullies are a policy of intimidation, intimidation and threats

Bullying is divided into three main types: verbal bullying, physical bullying, and emotional bullying. Bullying occurs in many places on a daily basis that we see and practice in our daily life, such as bullying practiced in school, street, university, or home. Domestic violence is the basis for a person's bullying due to exposure to violence And beating by family and brothers, which leads to the person performing violent acts with other people.

Bullying is based on political bullying, and this type is through the imposition of a state by imposing what it wants on another state with military threat and force, bullying in schools that is carried out by isolating the student or the victim and intimidating and physically assaulting them, and bullying in the workplace which is bullying that occurs in companies and institutions from By harming the target employee and bullying the Internet, which is done through the use of information and means and techniques of communication such as text messages, blogs and games on the Internet by carrying out hostile action aimed at harming others, and the prank is a ritual test that is on No ill-treatment, harassment, abuse, and assault with the request of some meaningless tasks, military bullying that is done by using physical force, abusing power to harm others, giving unlawful punishments, and using the power granted in intimidation, and it should be noted that there is a strong relationship between bullying and suicide Because bullying leads to many suicides because people who commit suicide suffer from harassment and being bullied, so the way to deal with parents and children must be preserved because the way of dealing is what determines the child's personality since childhood.

The phenomenon of bullying is old-new and its causes are summarized in the family environment, the school environment, media platforms, negative social deposits and aggressive behavior that arises for some as a result.

We need the contribution and participation of all the bodies that constitute the causes of the phenomenon for the purpose of limiting it and developing effective solutions for it through proper education and the efforts of school administration, teachers, youth centers, informational and informative programs, and dialogue and communication 
workshops between youth and others, and we may need to follow the methods and methods of prevention from the phenomenon that are more effective and more A success of focusing on law enforcement and the imposition of penalties - albeit important - because prevention is better than a pound of treatment.

Therefore, everyone's contribution is required to change our societal culture so that the basis for it is respecting the other, not suppressing or excluding him, and possessing positive and not negative communication and communication skills, and focusing on the language of dialogue, tolerance, justice and equality, not societal violence, where bullying phenomenon is not only between school students but is present in the street, the family and students Universities, couples, and the workplace between adults and children, males and females, and acknowledging their existence is considered the first step to eliminate them.

It is also required to monitor the behavior of individuals by their institutions, such as the family, school, university, and others, in order to contribute to avoiding the phenomenon for the next generation.

Finally, bullying is an aggressive behavior that creates an abnormal generation, and we all have institutions and individuals to contribute each according to its ability to protect society and the future generation from the phenomenon that offends us and our society and discredits our educational, social, youth and other institutions, so let us contribute to a bright image of the homeland that is free from violence, fears, royalties, bullying, etc. . 